Artículo original

\title{
EVALUACIÓN SENSORIAL Y ESTUDIO DE LA VIDA ÚTIL DE TÉ AROMÁTICO ELABORADO A BASE DE LLANTÉN (PLANTAGO MAJOR L.), CANELA (CINNAMOMUM VERUM) Y LIMÓN SUTIL (CITRUS AURANTIFOLIA SWINGLE)
}

"SENSORY EVALUATION AND STUDY OF THE SHELF LIFE OF AROMATIC TEA MADE FROM PLANTAIN (PLANTAGO MAJOR L.), CINNAMON (CINNAMOMUM VERUM) AND SUBTLE LEMON (CITRUS AURANTIFOLIA SWINGLE)"

Martin Alonso Talavera Sardón ${ }^{1}$ Raul Cartagena Cutipa ${ }^{1,2}$

Información del artículo: Recibido: 20/06/2018. Aceptado: 29/11/2018

${ }^{1}$ Ingeniero Agroindustrial

${ }^{2}$ Doctor, Docente Facultad de Ingeniería, Universidad Privada de Tacna

INGENIERÍA

INVESTIGA 
Vol. $1, \mathrm{~N}^{\circ} 1$.

Julio - Diciembre del 2019. 


\section{Resumen}

El trabajo de investigación tuvo como objetivo evaluar las características sensoriales y la vida útil del té aromático elaborado a base de llantén (Plantago major L), canela (Cinnamomum verum) y limón sutil (Citrus aurantifolia swingle). Para obtener los resultados se evaluaron parámetros fisicoquímicos tales como: humedad y ceniza, también se realizaron los análisis microbiológicos tales como: Aerobios mesófilos y Coliformes totales; para la evaluación sensorial, los consumidores evaluaron seis tratamientos de diferentes concentraciones, donde se evaluó: Olor, sabor, color y aspecto general aplicado a treinta jueces. Los resultados mostraron que en el análisis fisicoquímico respecto a la humedad tuvo como promedio el $87 \%$ en llantén, $85 \%$ en limón y 5,35\% en canela, cenizas con un $1,79 \%$ en llantén, $0,46 \%$ en limón y $4,25 \%$ en canela, con respecto al análisis microbiológico de las muestras, el llantén tuvo como mayor nivel de contaminación un total de 7,1 x 104 UFC/g en análisis microbiológico de mesófilos aerobios siendo significativo con un $95 \%$ de probabilidad, además de predominancia en coliformes totales con un 1,27 x $104 \mathrm{UFC} / \mathrm{g}$. La evaluación sensorial dio como mejor promedio sensorial con 3,83 puntos interpretado como producto bueno correspondiente al tratamiento $\mathrm{T} 1$, teniendo como mayor relevancia el olor y el sabor con 3,87 puntos. Los análisis de varianza demuestran diferencias significativas entre sus promedios al $95 \%$ de probabilidad en cuanto a la evaluación sensorial; las características finales del té aromático a base de llantén, canela y limón fueron de 10,033 \% de humedad y 1,21 \% de ceniza. Para el estudio de vida útil del alimento, se utilizó el método de predicción matemática de Arrhenius, por lo que se obtuvo un tiempo de vida útil de 8,95 meses sometida a una temperatura de $25 \stackrel{\circ}{\mathrm{C}}$, dicho resultado es superior a las demás pruebas sometidas a 35 ㅇ C y $45 \stackrel{\circ}{\circ}$ con un tiempo de vida útil de 6,92 y 5,43 meses respectivamente, según el análisis de varianza (ANOVA) éstos resultados no presentan una relación estadísticamente significativa $(p=0,0524)$ entre la vida útil y la temperatura, con un nivel de confianza del $95 \%$.

Palabras claves: Llantén, Limón sutil, Canela, Evaluación Sensorial, Vida útil.

\section{Abstract}

The research work was aimed evaluate the sensory characteristics and shelf life of aromatic tea made from plantain (Plantago major L), cinnamon (Cinnamomum verum) and subtle lemon (Citrus aurantifolia swingle). To obtain the results, physicochemical parameters such as humidity and ash were evaluated. Microbiological analyzes were also carried out, such as: Mesophilic Aerobics and Total Coliforms; for the sensory evaluation, the consumers evaluated six treatments of different concentrations, where it was evaluated: Odor, taste, color and general appearance applied to thirty judges. The results showed that in the physicochemical analysis with regard to humidity, it had an average of $87 \%$ in plantain, $85 \%$ in lemon and $5.35 \%$ in cinnamon, ash with $1.79 \%$ in plantain, $0.46 \%$ in lemon and $4.25 \%$ in cinnamon, with respect to the microbiological analysis of the samples, the plantain had a higher level of contamination a total of $7.1 \times 104$ CFU / $g$ in microbiological analysis of aerobic mesophiles being significant with a $95 \%$ probability, besides predominance in total coliforms with $1.27 \times 104$ CFU / g. The sensory evaluation gave the best sensory average with 3.83 points interpreted as a good product corresponding to the T1 treatment, with the odor and taste being the most relevant with 3.87 points. Analysis of variance shows significant differences between their averages at $95 \%$ probability in terms of sensory evaluation; the final characteristics of the aromatic tea based on plantain, cinnamon and lemon were $10.033 \%$ humidity and $1.21 \%$ ash. For the study of the useful life of the food, the method of mathematical prediction of Arrhenius was used, for which a shelf life of 8.95 months was obtained, subjected to a temperature of $25{ }^{\circ} \mathrm{C}$, this result is superior to the other tests subjected to $35^{\circ} \mathrm{C}$ and $45^{\circ} \mathrm{C}$ with a shelf life of 6.92 and 5.43 months respectively, according to the analysis of variance (ANOVA) these results do not show a statistically significant relationship $(p=0.0524)$ between the useful life and the temperature, with a confidence level of $95 \%$.

Keywords: Plantain, Subtle lemon, Cinnamon, Sensory evaluation, Shelf life. 


\section{INTRODUCCIÓN}

En el campo alimentario a nivel mundial, existe una mayor tendencia de aceptación del consumo de hierbas aromáticas que poseen propiedades naturales que aportan a la salud, esto se debe a que el consumidor tiene un interés hacia ciertos cultivos que contienen nutrientes o sustancias fisiológicamente activas que proporcionan un beneficio en la mitigación de ciertas enfermedades. Al evaluar las características organolépticas que proporciona el producto, nos aseguramos que éstas puedan cumplir con las exigencias del consumidor, a esto se le denomina "aceptabilidad" lo cual se determina por medio de la evaluación sensorial basándose en la preparación de las pruebas, ejecución de muestras y la interpretación de resultados, obteniendo así un producto que cumpla con la satisfacción focalizado en el consumidor. Se ha determinado que el llantén (Plantago major) posee propiedades benéficas debido a un alto contenido de compuestos activos de mayor relevancia, dichas propiedades son de carácter antiinflamatorio, bactericida y cicatrizante empleándose como un té aromático para el consumo.

A partir de los años 70, la Organización Mundial de la Salud (OMS) ha identificado y reconocido la trascendencia de la medicina tradicional en la intervención de la salud, esto ha generado que en los países en desarrollo existan programas que orientan al fomento de la medicina tradicional, incluyendo elementos de sus compuestos activos y modos de preparación) en donde el llantén (Plantago major L.) es apreciado y citado en 9 de los 73 países.

Jumbo y Guevara (2016) investigaron la capacidad antioxidante y compuestos bioactivos de un filtrante de cinco hierbas aromáticas y esteviosido. De tal forma Millones, Mori, Bacalla, Vásquez y Tafur (2014) obtuvieron un filtrante de anís de monte (Tagetes filifolia Lag.) Según Pinto \& Bustamante (2008) evaluaron la actividad gastroprotectora de los extractos de llantén (Plantago major) Asimismo, Cholota (2011) estudia la menta (mentha arvensis) manzanilla (matricaria chamomilla), llantén (plantaginaceae) y malva (malváceas o malvaceae)" y encontró ausencia total de aerobios. De igual manera Vargas (2012) estudia el té base de plantas cedrón (aloysiacitrodora) y toronjil (mellisaofficinalis) procesado con stevia (steviarebaudiana bertoni). Según Arias (2007) obtuvo un producto elaborado a base de cáscaras de naranja (Té de cáscaras) que muchas veces son desperdicios, dando nuevas alternativas a las industrias dedicadas a procesar estas frutas. Asimismo, Wernert, Wagner, Gurni, Carballo y Ricco (2009) Estudiaron los polifenoles de infusiones y cocimientos de hojas de "Cedrón" (Aloysia citrodora Palau) y "Poleo" (Lippia turbinata Griseb.) -Verbenaceae;empleados en la medicina tradicional, bajo la forma de infusión y cocimiento (decocción) de sus hojas, principalmente en el tratamiento de desórdenes gastrointestinales. También Castañeda, Ramos e Ibáñez (2008) Investigaron la capacidad antioxidante de siete plantas medicinales peruanas, evaluando la capacidad antioxidante de veintinueve extractos de las siguientes plantas medicinales: Cinnamomum zeylanicum "canela", Calophyllum brasiliense "lagarto caspi", Myrciaria dubia "camu camu", Minthostachys mollis "muña", Alchornea castaneifolia "hiporuro", Smallanthus sonchifolius "yacón", Lepidium 
Se denomina aromático a todas aquellas plantas, flores, hojas, raíces o frutos que desprenden perfumes que a la sensibilidad del olfato se reconocen como tal (MAGYA, 2014). En el siglo XVII hubo un realce en la importancia de las plantas medicinales y aromáticas por el uso por ejemplo del anís estrellado de China (Fretes et al., 2010). Al tener sustancias químicas conocidos como "principios activos" mencionadas anteriormente, sabemos que éstas ejercen una acción farmacológica sobre todo por la capacidad de sus esencias que se encuentran dentro de la planta. (Castro, 2013).

EI LLANTÉN (Plantago Major L.) es una hierba perenne, decidua, con tallo de 25 a 40 $\mathrm{cm}$ de altura. Floración de flores blancas, perfectas, pequeñas, en número de una o más, agrupadas en espigas densas, largas, delgadas, que se elevan sobre escapos desnudos. (Instituto Politécnico Nacional, 2010). Según Raad, 2009. contiene mucílagos (3-6\%), pectinas, sustancias amargas, taninos, aceite esencial, tiene sal de potasio (un $0,5 \%$ ), enzimas (invertina y emulsina), saponinas, vitamina C, flavonoides (plantaginina) y ácidos orgánicos (cítrico y málico). Se pueden utilizar tanto la inflorescencia como las semillas, esto se debe a la actividad antiinflamatoria causada por la irritación por ejemplo la conjuntivitis, además su uso es potencialmente usado en tratamiento con quemaduras y picaduras de insectos. (Stuart, 1981). Los mucílagos presentes en el Llantén tienen un efecto emoliente, expectorante y reduce la absorción intestinal de hidratos de carbono y lípidos. El efecto antiinflamatorio presente en el llantén es gracias a los glucósidos iridoides presentes. Los taninos tienen actividad astringente y el aprovechamiento de las semillas se debe a su acción laxante, algunos compuestos puros que se encuentran en el extracto de la planta mostraron una potente actividad antiviral (Chiang, 2003). Entre ellos, el ácido cafeico mostró una fuerte actividad contra el virus del herpes y adenovirus y el ácido clorogénico mostró que la actividad contra el adenovirus es efectiva. (Chiang, 2002). Según MINAGRI 2017, el limón es un cultivo permanente, el cual se siembra y cosecha todo el año, principalmente en la zona norte del país. Las variedades que se producen son el limón Sutil y el limón Tahití. Su capacidad antioxidante ayuda a mitigar enfermedades y/o sustancias cancerígenas como las nitrosaminas, ejerciendo la importancia de la prevención del cáncer (Mapama, 2008). Existe fibra soluble encontrada en el limón como la pectina, esta se encuentra como una capa blanca debajo de la corteza. Sin embargo, los componentes como los fitonutrientes son los más destacados; el compuesto localizado en la corteza llamado limonoides es el responsable de contribuir a la prevención frente a algunos tipos de cáncer, siendo el monoterpeno d- limoneno el más abundante. (Ailimpo, 2012).

La CANELA (Cinnamomum verum), según Lorenze \& Mattos, 2002, se describe como Cinnamomum ssp. Es obtenida del árbol del canelo o la canela, canelero o Ceilán, árbol o arbusto perennifolio con corteza papirácea. Presenta hojas perennes, con 3 venas prominentes, simples y largas aromáticas. (Ranasinghe P. et al., 2012). Es originaria de Sri Lanka que es un país peninsular ubicado al sureste de la India. (Ravindran, 2004). Composición Química. Al ser consumida como una ración de $1 \mathrm{~g}$ al 
día, tiene contenido de hierro y calcio considerable, siendo equivalente al $4 \%$ de las ingestas recomendadas al día (IR/día) para el hierro, en hombres de 20-39 años con actividad física moderada, $2 \%$ mujeres y al 1,2\% de las IR/día para el calcio en esta población diaria (Consenso de la Sociedad Española de Nutrición Comunitaria, 2011).

\section{OBJETIVOS}

- Analizar la vida útil del té aromático a base de llantén, canela y limón.

- Evaluar las características sensoriales del té aromático elaborado a base de llantén, canela y limón.

- Determinar las concentraciones adecuadas de llantén, canela y limón.

\section{METODOLOGÍA}

El diseño fue experimental con mezclas de vértices extremos, el cual estudió los efectos del Llantén, canela y limón en 6 corridas. (Fig. 1). Se realizó Análisis Sensorial, Análisis microbiológico y Análisis físico-químico. Para la evaluación sensorial se empleó un Diseño de Bloques Completamente al Azar (DBCA) con 30 panelistas, quienes evaluaron los atributos del olor, color, sabor y aspecto general de las infusiones aromáticas utilizando una escala global del 0 al 5 para las características sensoriales, tales resultados se realizó un análisis de varianza y la prueba de Duncan al 95 \% para la comparación de las medias. Se determina la seguridad microbiológica y los parámetros de calidad del producto a estudiar según la Norma Técnica Ecuatoriana NTE INEN 2 392:2007. 


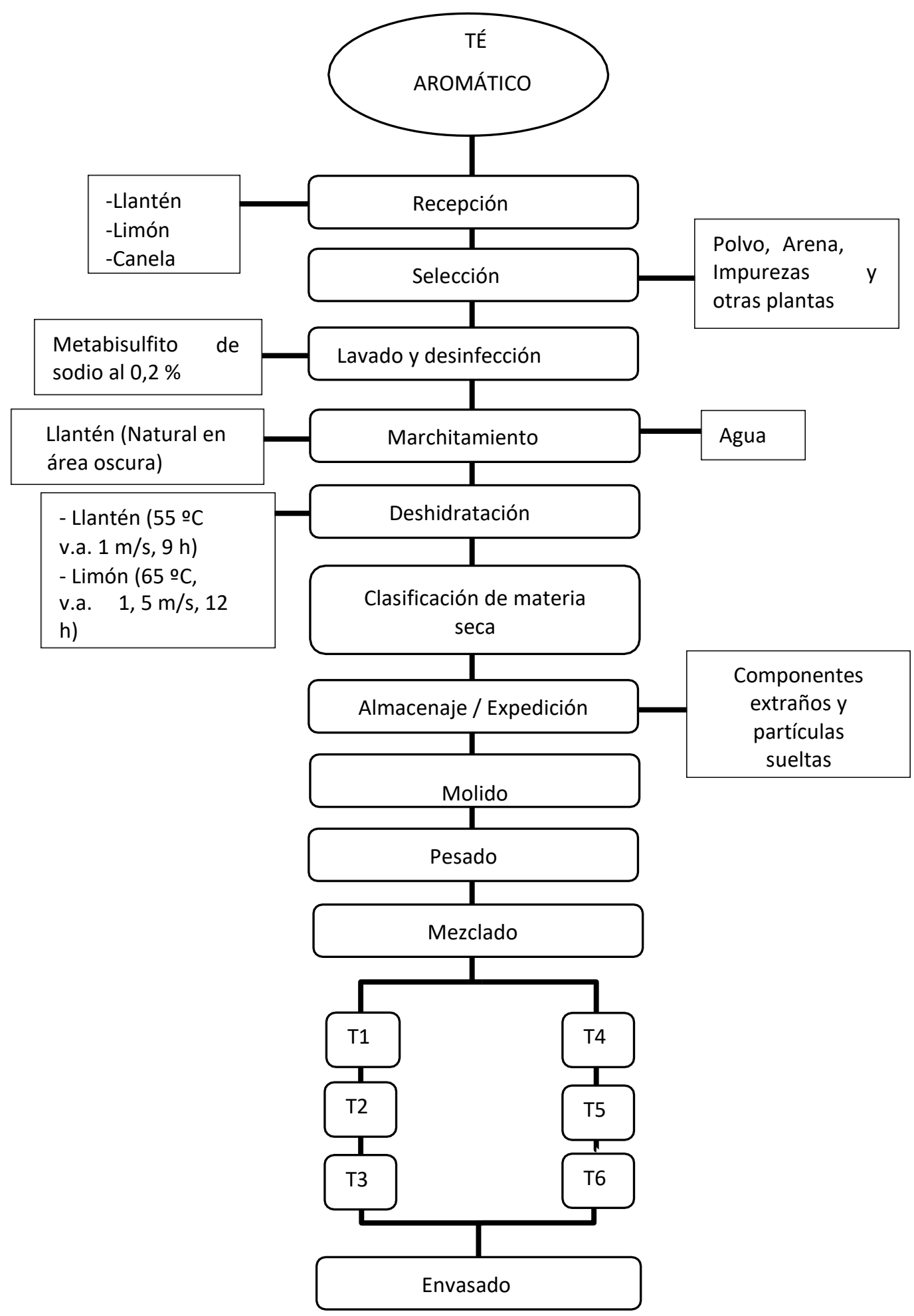

Fig. 1: Plan de diseño 


\section{RESULTADOS}

En la tabla 1 se reporta la determinación de la humedad inicial y final de las muestras, teniendo el llantén un mayor porcentaje de humedad con un promedio de $86,88 \%$, seguidamente el limón con un $85,15 \%$ de promedio y al final la canela con un promedio de $5,35 \%$. Respecto a la humedad final después del proceso de secado de las muestras El limón tuvo un promedio mayor de humedad con un 10,7 \%, seguido del llantén con un 9,6\%.

Tabla 1. Determinación de humedad inicial y final de las muestras de llantén, canela y limón.

\begin{tabular}{ccc}
\hline Muestra & Ho \% & H1 \% \\
\hline Llantén & $86,88 \%$ & $9,58 \%$ \\
Limón & $85,15 \%$ & $10,7 \%$ \\
Canela & $5,35 \%$ & ----- \\
\hline
\end{tabular}

Se mide la determinación de ceniza de cada materia prima; los valores promedios obtenidos para la canela fueron de $4.25 \%$, para las muestras de llantén y limón presentaron un promedio de $1.79 \%$ y $0.46 \%$ respectivamente. Se encuentran diferencias significativas entre los promedios de recuento de colonias de bacterias aerobias entre la muestra de llantén, canela y limón. Existe un porcentaje alto de población microbiana proveniente de las bacterias gram-negativas, lo cual indica una alta contaminación posiblemente en la calidad del agua o del propio alimento, esto podría ser posible debido a que no contempla condiciones de manejo agrícola, además de considerar que es un herbáceo de porte pequeño cercano al suelo.

Para la evaluación sensorial del té aromático se consideró un panel de cata global conformado por 30 personas, las cuales evaluaron los criterios propuestos con una escala de puntuación existindo una diferencia entre la aceptación de los tratamientos descritos en el promedio de cada uno; aunque es notorio que existe una preferencia entre los tratamientos, las pruebas estadísticas nos mostrarán si es significativo la diferencia entre ellos, por lo que ratificará dicha preferencia en uno de los tratamientos. (p:0.001)

Se realizó la prueba de subgrupos homogéneos al agrupar en columnas aquellos grupos que no difieren significativamente. Se observa que la prueba de Duncan ha agrupado los tratamientos T6, T5, T3, y T4 en una misma columna; T3, T4 y T2 en otra columna y T2 y T1 en una tercera columna. De esta forma gráfica deducimos qué subgrupos son homogéneos y cuáles difieren significativamente.

La predicción de la vida útil del alimento se realizó por el método de Arrhenius para cada una de las temperaturas en las que se almacenaron las muestras. Se hizo una regresión lineal de los valores de ufc/g de mohos y levaduras con el tiempo de almacenamiento (Tabla 2). Se muestran los resultados del recuento de mohos y 
levaduras para la predicción de vida útil del té aromático (expresado en $10^{1} \mathrm{ufc} / \mathrm{g}$ ), debido a la ausencia de microorganismos en las diluciones a la $10^{2}, 10^{3}$ y $10^{4}$ se consideró solamente la primera dilución.

Tabla 2. Resultado del recuento de mohos y levaduras para la predicción de vida útil del té aromático (expresado en $10^{1} \mathrm{ufc} / \mathrm{g}$ ).

\begin{tabular}{cccccc}
\hline 25 C & ufc/g & $\begin{array}{l}\text { Tiemp } \\
\text { o } \\
\text { (horas) }\end{array}$ & $\begin{array}{c}\text { ufc/ } \\
\text { (horas) }\end{array}$ & $\begin{array}{l}\text { Tiempo } \\
\text { (horas) }\end{array}$ & ufc/g \\
\hline 24 & 2 & 24 & 2 & 24 & 2 \\
96 & 2 & 96 & 2 & 96 & 3 \\
192 & 2 & 192 & 3 & 192 & 3 \\
288 & 2 & 288 & 3 & 288 & 3 \\
384 & 3 & 384 & 3 & 384 & 4 \\
480 & 3 & 480 & 4 & 480 & 5 \\
576 & 3 & 576 & 4 & 576 & 5 \\
\hline
\end{tabular}

Del mismo modo en la tabla 3 se observa los resultados de la reacción de primer orden que es necesario para realizar nuestra ecuación de regresión lineal para determinar nuestra pendiente.

Tabla 3. Resultados de reacción de primer orden del recuento de colonias de Mohos y levaduras (expresado en $10^{1} \mathrm{ufc} / \mathrm{g}$ ).

\begin{tabular}{|c|c|c|c|c|c|c|c|c|}
\hline & $25 \stackrel{\circ}{C}$ & & & $35 \stackrel{\circ}{\circ}$ & & & & $45 \stackrel{\circ}{ } \mathrm{C}$ \\
\hline $\begin{array}{l}\text { Tiempo } \\
\text { (horas) }\end{array}$ & ufc/g & $\operatorname{Ln}($ ufc/g) & $\begin{array}{l}\text { Tiempo } \\
\text { (horas) }\end{array}$ & ufc/g & $\operatorname{Ln}(\mathrm{ufc} / \mathrm{g})$ & $\begin{array}{c}\text { Tiemp } \\
\text { o } \\
\text { (horas) }\end{array}$ & ufc/g & $\operatorname{Ln}($ ufc/g) \\
\hline 24 & 2 & 0,6931471 & 24 & 2 & 0,6931471 & 24 & 2 & 0,69314718 \\
\hline 96 & 2 & 0,6931471 & 96 & 2 & 0,6931471 & 96 & 3 & 1,09861228 \\
\hline 192 & 2 & 0,6931471 & 192 & 3 & 1,0986122 & 192 & 3 & 1,09861228 \\
\hline 288 & 2 & 0,6931471 & 288 & 3 & 1,0986122 & 288 & 3 & 1,09861228 \\
\hline 384 & 3 & 1,0986122 & 384 & 3 & 1,0986122 & 384 & 4 & 1,38629436 \\
\hline 480 & 3 & 1,0986122 & 480 & 4 & 1,3862943 & 480 & 5 & 1,60943791 \\
\hline 576 & 3 & 1,0986122 & 576 & 4 & 1,3862943 & 576 & 5 & 1,60943791 \\
\hline
\end{tabular}

Así mismo en la figura 2, 3 y 4 se aprecia la regresión lineal de primer orden correspondiente a la temperatura de $25 \stackrel{\circ}{ } \mathrm{C}, 35$ y $45 \stackrel{\circ}{ } \mathrm{C}$ respectivamente. La importancia de la regresión lineal es la pendiente de la recta que es la constante de velocidad de reacción. 


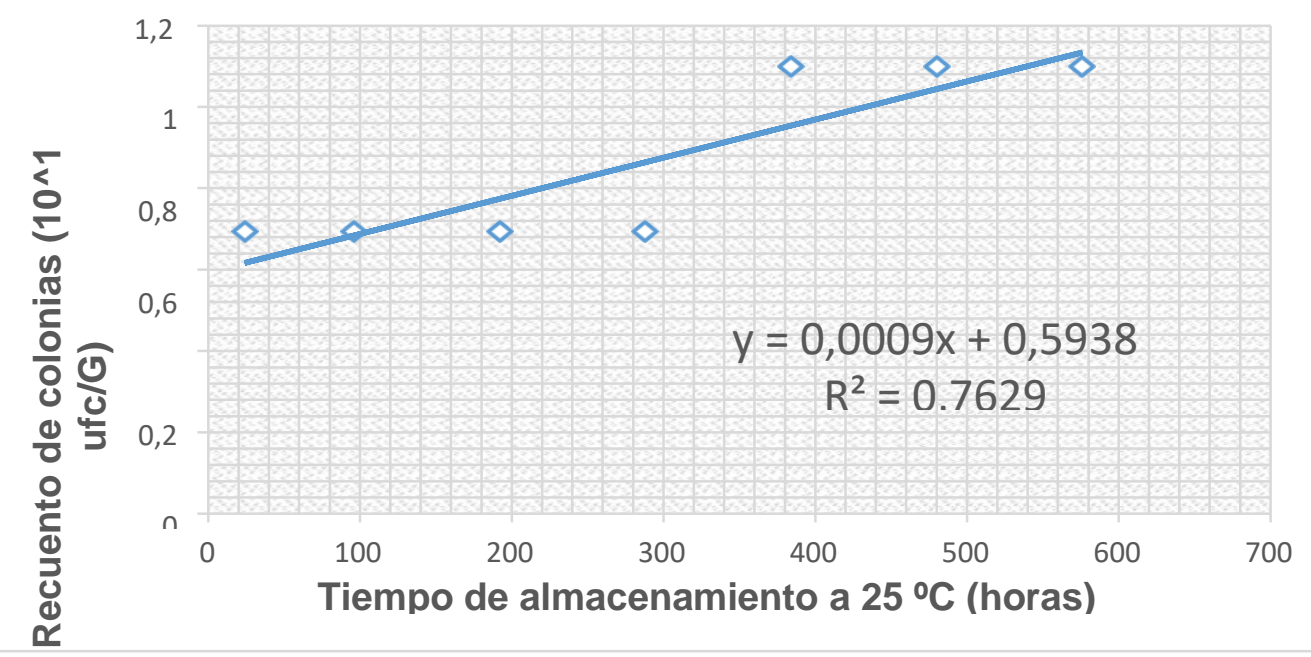

Figura 2. Recuento de mohos y levaduras en función al tiempo de almacenamiento para 25 oC

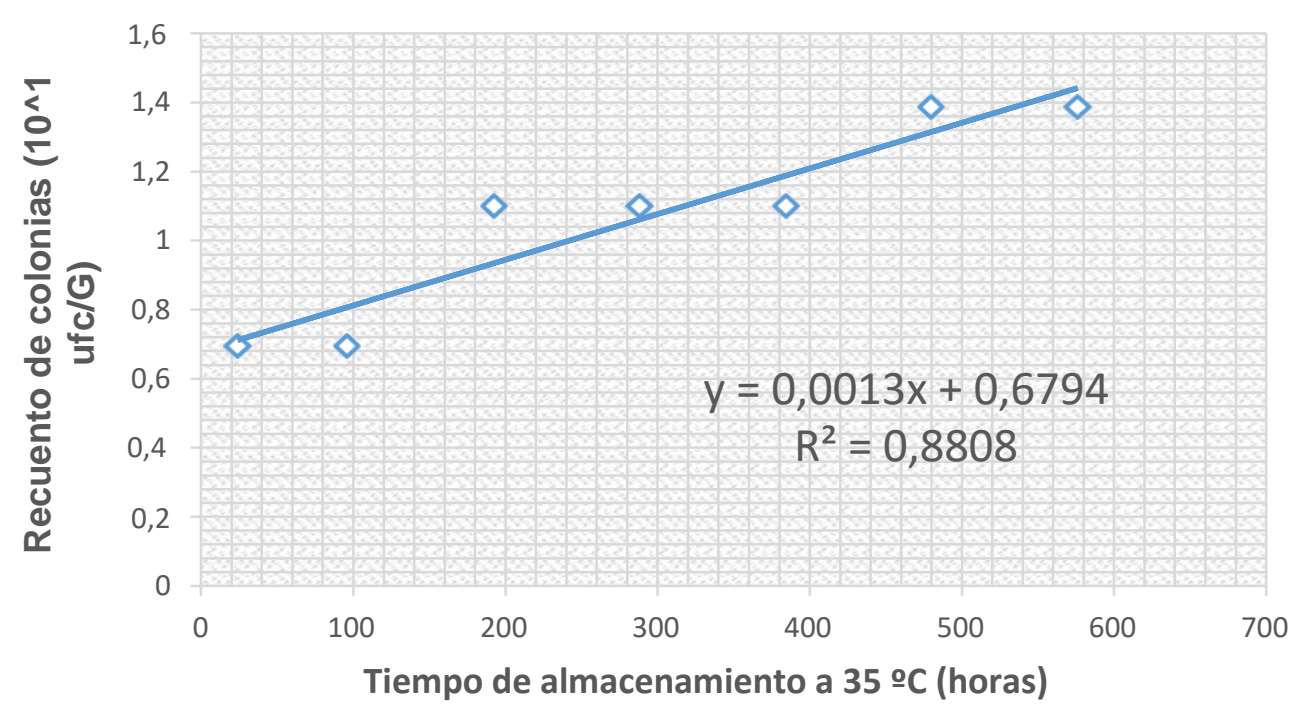

Figura 3. Recuento de mohos y levaduras en función al tiempo de almacenamiento para 35 ㄷ․

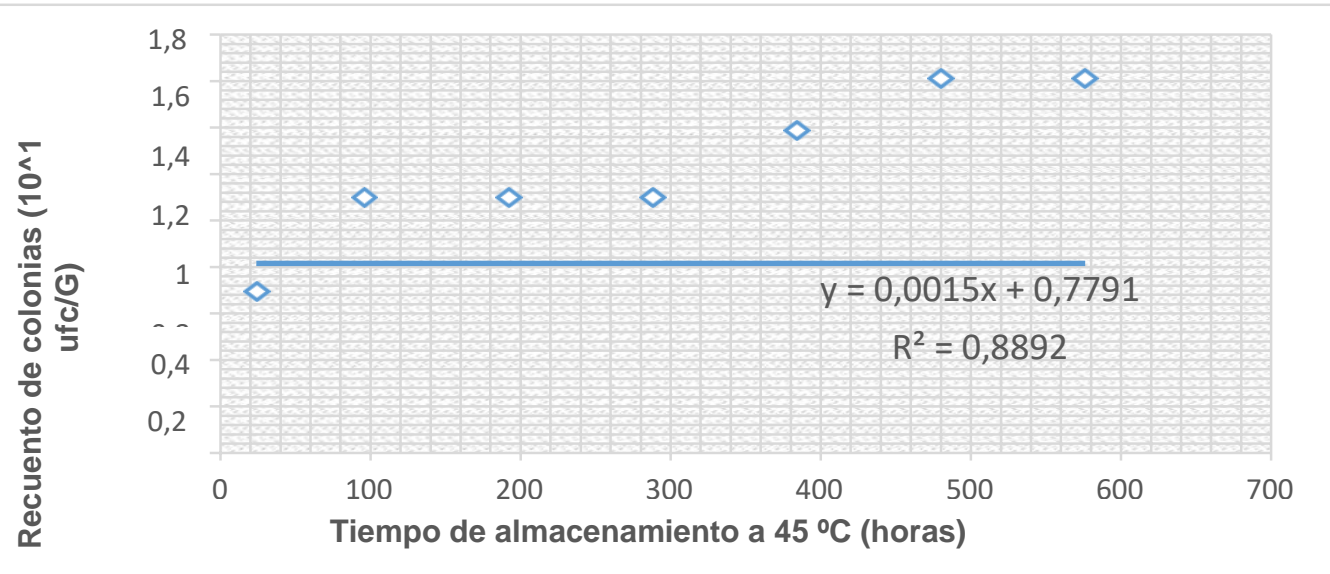

Figura 4. Recuento de mohos y levaduras en función al tiempo de almacenamiento para 35 ㄷ. 


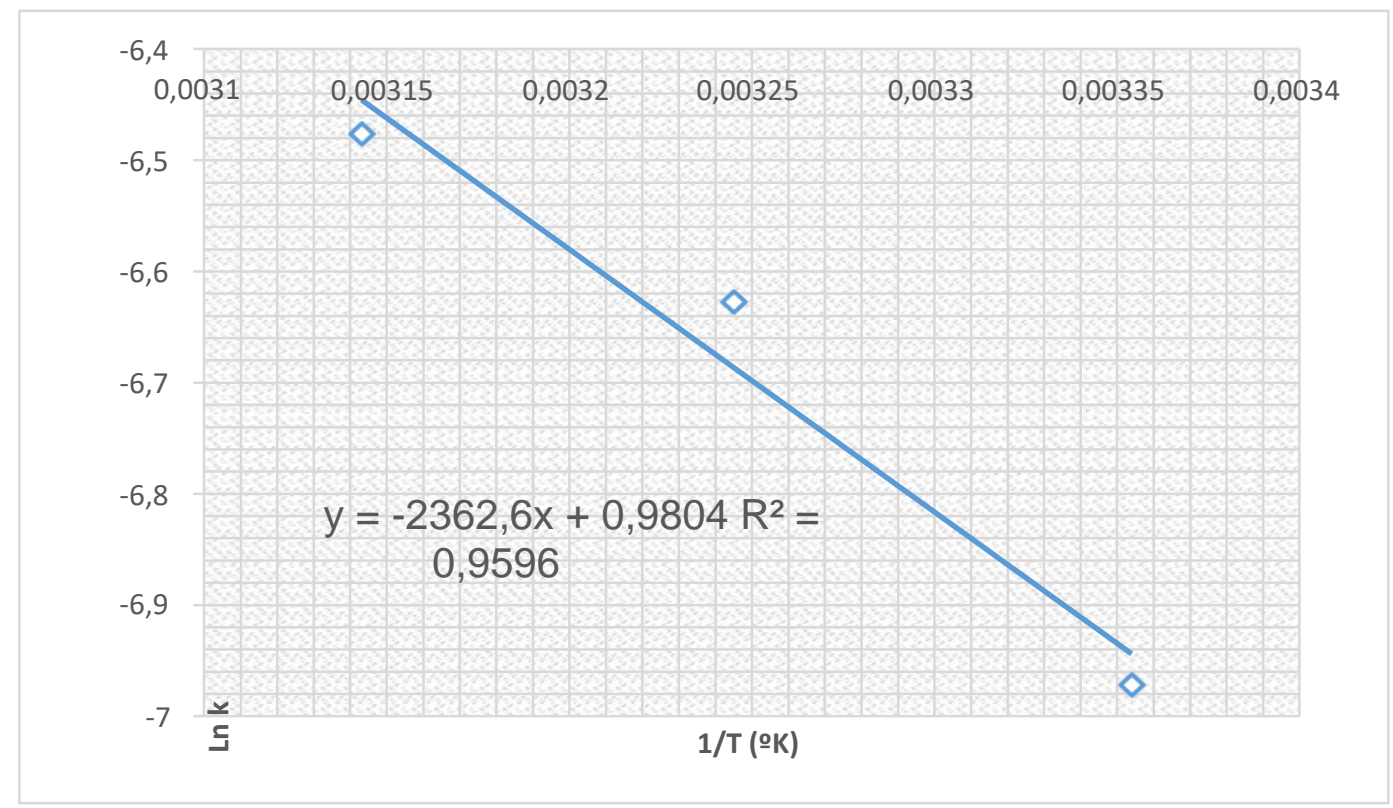

Figura 5. Logaritmo natural de k en función de la inversa de la temperatura

En la Fig. 5 se observa la ecuación y mediante ella podremos calcular el tiempo necesario para que la cantidad de colonias de mohos y levaduras (expresados en ufc/g) llegue a cierto valor inaceptable a cierta temperatura. Los valores de energía de activación y factor pre exponencial que se han obtenido anteriormente nos permiten calcular el valor de la constante de reacción a $25^{\circ} \mathrm{C}, 35^{\circ} \mathrm{C}$ y $45^{\circ} \mathrm{C}$.

La predicción de vida útil calculada para la ecuación matemática de Arrhenius para la muestra del té aromático es de 6443,62 horas ( 8,95 meses) sometida a una temperatura de 25 ㄷ $\mathrm{C}$ envase primario de papel filtrante; al realizarse el estudio en un periodo de 576 horas $(<30$ días) de almacenamiento, podremos afirmar que la muestra de té aromático a base de llantén, canela y limón es aún apto para el consumo humano, por lo que se encuentra dentro de los parámetros de vida útil en la investigación.

Por lo tanto, la muestra de té aromático sometida a una temperatura de 35 ㄷ presenta una vida útil de 4982,51 horas (6,92 meses) en envase primario de papel filtrante, también podremos afirmar que nuestro alimento aún es apto para el consumo humano debido a que se encuentra dentro de los parámetros de vida útil en la investigación.

Para la temperatura de 45 C presenta una vida útil de 3915,49 horas $(5,44)$, aunque siendo menor la predicción de vida útil calculada, dicha muestra aún es apta para el consumo humano debido a que se encuentra dentro de los parámetros de vida útil en la investigación. A $25^{\circ} \mathrm{C}$ se obtiene un tiempo de vida útil más largo ( 8,95 meses) que la muestra sometida a $45^{\circ} \mathrm{C}$ con un tiempo de vida útil a 5,44 meses. La ecuación de la tabla 4 representa el modelo lineal ajustado de la vida útil que describe la relación entre la vida útil del producto y la temperatura, donde los valores que se estiman con el modelo, determinarán los valores maximizados de vida útil (meses). 
Vida útil meses $=13,1917-0,175 *$ temperatura.

Para comprobar la significancia de la vida útil sobre la temperatura, se realizó un análisis de varianza (ANOVA), tal como se muestra en la tabla 20; por lo que se evidencia que no existe una relación estadísticamente significativa $(p=0,0524)$ entre la vida útil y la temperatura, con un nivel de confianza del $95 \%$.

Tabla 4. Análisis de Varianza de la vida útil en relación al a temperatura

\begin{tabular}{llllll}
\hline Fuente & $\begin{array}{l}\text { Suma de } \\
\text { Cuadrados }\end{array}$ & Gl & $\begin{array}{l}\text { Cuadrado } \\
\text { Medio }\end{array}$ & Razón- F & Valor-P \\
\hline Modelo & 6.125 & 1 & 6.125 & 147.00 & 0.0524 \\
Residuo & 0.0416667 & 1 & 0.0416667 & & \\
Total & 6.16667 & 2 & & & \\
(Corr.) & & & & & \\
\hline
\end{tabular}

\section{DISCUSIÓN}

Durante la investigación, se ha observado que la composición físico-química del té aromático a base de llantén, canela y limón en relación a la humedad presenta un promedio de 10,03\%, siendo un valor similar a lo hallado por Vargas (2012) que reportaba un valor de $10,08 \%$ de un té aromático elaborado a base de cedrón, toronjil y stevia, al igual que Cholota (2011) en su investigación demostró un promedio de 9,84 \% de humedad en la elaboración de un té medicinal nutracéutico a base de plantas ancestrales, sin embargo Jumbo y Guevara (2016) obtuvieron un promedio de 5,63 \% de humedad en la elaboración de un filtrante de cinco hierbas aromáticas, aun siendo una humedad relativamente menor a las demás, según la Norma Técnica Ecuatoriana (INEN 2 392:2007) establece para el té aromático o té de hierbas un máximo de $12 \%$ de humedad, resultado que asegura la inhibición del crecimiento microbiano y mantiene estable la infusión. En cuanto a la obtención de cenizas del té aromático, su promedio es de 1,21\%, resultado inferior a lo obtenido por Flores y Cochama (2014) con un promedio de 2,65 \% de ceniza en el alimento instantáneo a base de gritz de cañihua, maíz morado y oca negra; estos resultados se deberían probablemente al tipo de suelo agrícola que incrementa de forma indirecta el contenido de minerales tales como calcio o potasio dentro de la composición de la materia prima para la elaboración de un producto.

Según los resultados con respecto a la evaluación sensorial, el tratamiento T1 empleando un 96,5 $\%$ de llantén, 1,5\% de canela, y un 2,0 \% de limón, fue el que mayor aceptabilidad tuvo entre los panelistas, Millones et al. (2014) mencionan que al emplear una temperatura de 60-65 ㄷ en el proceso de secado de hierbas aromáticas, preservan las propiedades de las plantas aromáticas tales como el olor y sabor, sin embargo, Vargas (2012) determinó que el mejor tratamiento se realizó de forma natural y no sometido a un deshidratador, mencionando que la materia prima no perdió sus características organolépticas y físicas, sino que se mantuvo en adecuadas 
condiciones; en nuestra investigación, según el panel de jueces para la evaluación sensorial, determinaron que el olor y el sabor destacaron en el tratamiento $\mathrm{T} 1$, teniendo en consideración que el limón sutil y la canela aportan características organolépticas agradables, tal como lo menciona Chávez y Fuentes (2009) al referirse que la cáscara de limón aporta un sabor ácidoamargo al producto al igual que la canela aporta un aroma más estable en el té aromático.

Cholota (2011) Menciona que el análisis sensorial es de mucha importancia, ya que podemos identificar la preferencia de los catadores al combinar diversas plantas, determinando que la mejor formulación es la que presenta los mejores atributos del producto.

Según los resultados de la predicción de vida útil calculado mediante el método de Arrhenius para la muestra de té aromático a base de llantén, canela y limón; se obtuvo un tiempo de vida útil de 8,95 meses sometida a una temperatura de $25 \stackrel{\circ}{\circ}$, dicho resultado es superior a las demás pruebas sometidas a 35 ㄷ y 45

oC con un tiempo de vida útil de 6,92 y 5,43 meses respectivamente. Este resultado es contrastado con la investigación de Cholota (2011) en la elaboración de un té medicinal nutracéutico a base de plantas ancestrales, teniendo un resultado de vida útil de 9 meses en condiciones de almacenamiento a 18 C; este resultado es calculado por la ecuación de Heldman y Singh (1984) de la cinética de reacción de primer orden. Los datos bibliográficos señalan un tiempo de consumo de un té comercial que puede durar hasta 2 años según las condiciones de almacenamiento, para ambas investigaciones, el resultado de tiempo de vida útil es menor y se debería a dos posibles condiciones:

La primera condición correspondería al tipo de envase utilizado, siendo el envase primario un papel filtrante termosellable para ambas investigaciones, por lo que al ser un material semipermeable, separa la sustancia de las partículas sólidas que no se consumen, por lo que el producto estaría expuesto a posibles agentes alteradores presentes en el entorno (microorganismos, humedad, etc) y como consecuencia, alteraría las características iniciales del producto según los parámetros establecidos por la norma, para ello, las marcas comerciales utilizan un envase primario, secundario y un empaque para mantener la calidad inicial y prolongar la vida útil del producto. Según Flores y Cochama (2014) para su producto elaborado a base de cañihua, maíz morado y oca como alimento instantáneo, el tiempo de vida útil más largo se obtuvo de un tratamiento envasado en polietileno de aluminio laminado siendo el resultado de 7,87 meses, y el más corto fue de un tratamiento envasado en polietileno opaco coextruido bilaminado siendo elresultado de 5,78 meses, considerando en conclusión que existe una diferencia en la conservación del alimento en distintos envases, solventando que es recomendable utilizar un envase adecuado que prolongue la vida útil del alimento elaborado.

La segunda condición correspondería al proceso de elaboración del alimento, siendo uno de los puntos estratégicos el proceso de irradiación, ya que dicho proceso reduce a niveles aceptables la carga microbiana; Jumbo y Guevara (2016) afirman en su investigación del filtrante elaborado a base de cinco hierbas aromáticas, que la carga microbiana antes de la irradiación fue de $10 \times 10^{3}$ ufc/g, esto se debería a que no se realizó un proceso de limpieza y desinfección a la materia prima, por lo que sólo se realizó un proceso de secado o deshidratación; sin embargo, la carga microbiana después del proceso de irradiación fue menor a $10 \mathrm{ufc/g}$ teniendo un alcance 
considerable en la eliminación de mohos y levaduras. Para Zhang et al. (2010) dicho proceso permite la destrucción de los microorganismos que alteran la calidad del producto, sin embargo, recomienda siempre poder combinar con otros tratamientos para optimizar la prolongación de las características iniciales del producto.

\section{CONCLUSIONES}

Se evaluó sensorialmente los seis tratamientos de diferentes concentraciones de té aromático a base de llantén, canela y limón presentando los siguientes resultados: El mejor promedio sensorial con 3,83 puntos corresponde al tratamiento T1, seguido del tratamiento T2 con 3,67 puntos interpretado como Satisface favorablemente los requisitos de aceptabilidad. Asimismo, los análisis de varianza determinan diferencias significativas entre sus promedios al $95 \%$ de probabilidad.

Se determinó las concentraciones adecuadas de llantén, canela y limón según el mejor promedio siendo las concentraciones: Ilantén con $96,5 \%$, canela con $1,5 \%$ y limón con un 2,0 $\%$ correspondientes al tratamiento 1.

Se analizó la vida útil del alimento utilizando el método de predicción matemática de Arrhenius, obteniendo un tiempo de vida útil de 8,95 meses sometida a una temperatura de

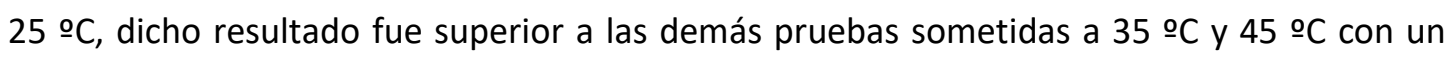
tiempo de vida útil de 6,92 y 5,43 meses respectivamente, éstos resultados no presentan una relación estadísticamente significativa $(p=0,0524)$ entre la vida útil y la temperatura, con un nivel de confianza del $95 \%$.

\section{RECOMENDACIONES}

Realizar una evaluación sensorial de un té aromático a base de Llantén (Plantago lanceolata) producido mayormente en las zonas alto andinas.

Se recomienda evaluar la influencia de distintos envases para el estudio de vida útil de un té aromático a base de hierbas nativas de la región.

Evaluar las características fisicoquímicas y microbiológicas de distintas variedades de llantén.

Se recomienda realizar un análisis comparativo de distintos procesos de secado para la obtención de deshidratado de llantén como producto sucedáneo.

\section{REFERENCIAS BIBLIOGRÁFICAS}

Arias M. (2007) “Proceso de fabricación de té de cáscaras de cítricos" UNIVERSIDAD DE CUENCA, Cuenca - Ecuador.

Asociación Interprofesional de Limón y Pomelo (Ailimpo), (2012) "Valor Nutricional de los limones" 2012 p. 10.

Caicedo E. y Otavalo S. (2007) "Determinación de temperatura y tiempo de deshidratación para la elaboración de té de sunfo, (Clinopodium nubigenum) (kunth) kuntze" Universidad 
Técnica del Norte, Ibarra- Ecuador.

Castañeda C. B., Q.F. Ramos LL. E., Ibáñez V. L. (2008) "Evaluación de la capacidad antioxidante de siete plantas medicinales peruanas" Horizonte Médico, vol. 8, núm. 1, junio, 2008, pp. 56-72 Universidad de San Martín de Porres La Molina, Perú.

Castro Restrepo, D., (2013) "Cultivos y producción de plantas aromáticas y medicinales". 2da edición. Rionegro: Universidad Católica oriente, 201394 pp.

Charm, S.E. (2007). "Ingeniería de alimentos aplicada para adaptarse a las regulaciones, calidad y pruebas de alimentos". Alimentos Ciencia e Ingeniería. 16 (1):5-8.

Chiang, L. C. et al W. (2003) "Efectos in vitro citotóxicos, antivirales e inmunomoduladores de Plantago major y Plantago asiática". El Diario estadounidense de medicina china (AJCM). 2. ed. v. 31, 2003. p. 225-234.

Chiang, L. C. et al. (2002) "Actividad antiviral de extractos de Plantago major y compuestos relacionados in vitro. Investigación antiviral", v.55, n. 1, p. 53-62.

Cholota J. (2011) "Obtención de té medicinal nutracéutico a partir de plantas ancestrales menta (mentha arvensis) manzanilla (matricaria chamomilla) Ilantén (plantaginaceae) malva (malváceas o malvaceae)" Universidad Técnica de Ambato, Ambato- Ecuador.

Consenso de la Sociedad Española de Nutrición Comunitaria (2011), "condimentos y aperitivos" P. 568.

Fernández-Pola, J. (1996) "Cultivo de plantas medicinales, aromáticas y condimeticias". Ediciones Omega, S.A. Barcelona.

Flores C., Cochama F. (2014) "Determinación de vida útil en alimento instantáneo a base de cañihua (Chenopodium pallidicaule Aellen), maíz morado (Zea mayz L.) y oca (Oxalis tuberosa) por pruebas aceleradas de almacenamiento y estabilidad de los compuestos bioactivos." Universidad Nacional de San Antonio de Abad del cusco, Facultad de ingeniería Agroindustrial.

Fretes, Francisco., Mendoza, C., Penner, R., Martinez, M., (2010) "Plantas medicinales y aromáticas una alternativa de producción comercial" Agencia del Gobierno de los Estados Unidos para el Desarrollo Internacional (USAID).

Giralda, G. G. I. (1999). "Métodos de estudio de vida de anaquel de los alimentos".

Monografía. Universidad Nacional de Colombia Sede Manizales.

Instituto Politécnico Nacional, (2010) "Farmacopea homeopática de los Estados Unidos Mexicanos". México, D.F., MX: ProQuest ebrary. Web. 16 November 2016.

Jumbo N., Guevara A. (2016) "Capacidad Antioxidante Y Compuestos Bioactivos de un filtrante de cinco Hierbas Aromáticas Y Esteviosido (Stevia Rebaudina B)". Recuperado de http://revistas.ups.edu.ec/index.php/granja/article/view/310/1141.

Krishnamoorty B. \& Rema J., (2004). "Usos de la canela y la cassia". Editorial CRC. Primera 
edición. 311-327 pp. Kerala, India.

Labuza, T.P., Riboh, D. (1982). "Teoría y aplicaciones de la cinética de Arrhenius para la predicción de pérdidas de nutrientes en alimentos". Food Technology, 36, 66-74.

Labuza, T.P., Fu, B. (1993). "Growth kinetics for shelf-life predictions: theory and practice". J. Ind. Microbiol., 12, $309-323$.

Labuza, T.P., (1994). "Determination of the Shelf Life of Foods". Article inedited.

Lorenze, H., Mattos, F.J.A., (2002) "Plantas Medicinales es Brasil - nativas y exóticas". Instituto Plantarum de Estudios de Flora Ltda.

Mapama, Ministerio de Agricultura, Alimentación y Medio Ambiente. (2008) “Cítricos.

Panel de hogares".

Martínez Maximino. (1959). "Plantas útiles de la flora mexicana". Editorial Botas. 112- 114 pp. México.

MAGYA Ministerio de la agricultura ganadería y alimentos (2014). "Aromas" Secretaría de producción agropecuaria familiar Gobernador Roca esq. La Coruña, Parque Sarmiento, Córdoba.

Millones C., Mori G., Bacalla J., Vásquez E. \& Tafur R. (2014) “Obtención de un filtrante de anís de monte (Tagetes filifolia Lag.) Edulcorado con hojas de estevia (Stevia rebaudiana Bertoni)" Recuperado de www.sci- agropecu.unitru.edu.pe

Ministerio de agricultura y riego: Dirección general de políticas agrarias (2017) "informe del limón" Dirección de Estudios Económicos e Información Agraria Julio 2017.

Mondino M \& Ferratto J. (2006) "El análisis sensorial, una herramienta para la evaluación de la calidad desde el consumidor" Revista Agro-mensajes, ediciones anteriores, Universidad Nacional del Rosario - Argentina.

Moreira O, Carbajal A, Cabrera L, Cuadrado C. (2011) "Tablas de composición de alimentos". 15a ed. Pirámide, editor. Madrid.

Moreira O, Cabrera L, Carbajal A, Cuadrado C. (2013) "Tabla de composición de Alimentos. Canela Molida. In: Condimentos y Aperitivos". Ediciones pirámide; [567-8].

Muñoz López de Bustamante, F. (1987) "Plantas medicinales y aromáticas. Estudio, cultivo y procesado". Ediciones MundiPrensa. Madrid.

Murcia MA, Egea I., Romojaro F., Parras P., Jiménez AM., M. Martinez Tomé. (2004). “Evaluación de antioxidantes de las expecias para postres comparado con los aditivos alimentarios comunes. Influencia del proceso irradiación". J Agric Food Chem. 52:1872-81. Murcia, España.

Norma Técnica Ecuatoriana NTE INEN 2 392, (2007) “Hierbas Aromáticas. 
Requisitos" Primera Edición.

Raad, Karim. (2009). "Las plantas silvestres en la alimentación humana y animal", pp. 61-62 Editorial Brujas.

Ranasinghe P, Jayawardana R, Galappaththy P, Constantine G, de Vas Gunawardana N, Katulanda P. (2012) "Eficacia y seguridad del verdadero cinnamomum (cinnamomum zeylanicum) como agente farmacéutico en la diabetes: una revisión sistemática y un metanálisis". Diabet Med: 1480-90. Ravindran, P.N., Nirmal Babu, K. y M. Shylaja. (2004). "Cinnamon and Cassia. El género Cinnamomun". Editorial CRC Prensa LLC. Kerala, India.

Revista Mundo Nuevo. (2010) "Plantas medicinales: Llantén" Edición 75: Chile. Robertsob, Gordon L. (1993) "Food Packing. Marcel Dekker". New York.

Samuelsen AB. (2000). "Los usos tradicionales, constituyentes químicos y actividades biológicas de Plantago major L." Una revisión. J etnofarmacol.

Sánchez, C. (2005). "Producción y Comercialización de Cítricos”, ediciones Ripalme, Lima. p 25 a 29; $110,111$.

Sancho, J. (2011) "Introducción al análisis sensorial de los alimentos" Barcelona- España. Editorial alfa y omega. p. 329.

Singh, R., P. (2000). "Scientific Principtes of Shelf-Life Evaluation in MAN".

Stuart, M. (1981) "Enciclopedia de Hierbas y Herboristería". Barcelona: Ediciones Omega S. A., 1981. p. 241-242.

Vargas V. (2012) "Elaboración de té aromático a base de plantas cedrón (aloysiacitrodora) y toronjil (mellisaofficinalis) procesado con stevia (steviarebaudiana bertoni) endulzante natural, utilizando el método de deshidratación" Universidad Técnica de Cotopaxi, Latacunga - Ecuador.

Wernert M., Wagner M., Gurni A., Carballo M. \& Ricco R. (2009) "Estudio de polifenoles de infusiones y cocimientos de hojas de "Cedrón" (Aloysia citrodora Palau) y "Poleo" (Lippia turbinata Griseb.) -Verbenaceae" Boletín Latinoamericano y del Caribe de Plantas Medicinales y Aromáticas, vol. 8, núm. 4, julio, 2009, pp. 308-311.

Zhang, H., G. Barbosa, V. Balasubramaniam, P.Dunne, D. Farkas and J. Yuan. (2010 "Tecnologías de procesamiento erróneas para alimentos". Editorial WILEY- BLACKWELL. Nueva York 2: 664 . 